\title{
Idiopathic hypertrophic subaortic stenosis can be treated endoscopically
}

\author{
Filip Casselman, MD, PhD, FETCS, and Hugo Vanermen, MD, FETCS,
} Aalst, Belgium

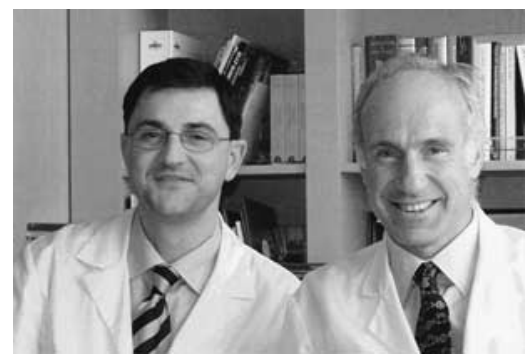

Casselman and Vanermen (left to right)
$\mathrm{I}$ diopathic hypertrophic subaortic stenosis (IHSS), when treated surgically, usually requires a full sternotomy. Although the procedure is fairly demanding because of limited exposure, excellent immediate and long-term results have been described with this approach. ${ }^{1}$ Less invasive endovascular approaches have been proposed to palliate this condition, but long-term follow-up is limited. , $3^{3}$ To increase surgical exposure, warrant an excellent result (as the surgical approach has provided thus far), and limit the invasiveness of the procedure, we recently performed a successful endoscopic resection of IHSS associated with mitral valve repair.

\section{Clinical Summary}

A 53-year-old female patient was given a diagnosis of IHSS 10 years ago. The left ventricular outflow tract gradient at that time was $30 \mathrm{~mm} \mathrm{Hg}$ at rest and $70 \mathrm{~mm} \mathrm{Hg}$ at exertion. The patient refused treatment.

The patient remained well until 4 months before admission, when she experienced a first syncope. In the following months, she had 3 more syncopes, angina developed, and her condition progressed to New York Heart Association functional class III, all of which prompted further investigation.

Physical examination revealed a grade 5/6 systolic murmur. Echocardiographic examination confirmed the subaortic stenosis with a resting gradient of $55 \mathrm{~mm} \mathrm{Hg}$, which increased to $95 \mathrm{~mm}$ $\mathrm{Hg}$ after ventricular extrasystole. The asymmetric end-systolic subaortic septal hypertrophy measured $35 \mathrm{~mm}$. There was a grade $1 / 4$ aortic valve regurgitation and a grade $2 / 4$ mitral valve regurgitation. No other abnormalities were seen.

From the Department of Cardiovascular and Thoracic Surgery, OLV Clinic, Aalst, Belgium.

Received for publication Feb 25, 2002; accepted for publication April 18, 2002.

Address for reprints: Filip Casselman, MD, PhD, FETCS, Department of Cardiovascular and Thoracic Surgery, OLV Clinic, Moorselbaan 164, 9300 Aalst, Belgium (E-mail: Filip.Casselman@olvz-aalst.be).

J Thorac Cardiovasc Surg 2002;124:1248-9

Copyright $\odot 2002$ by The American Association for Thoracic Surgery

0022-5223/2002 \$35.00+0 $\quad \mathbf{1 2 / 5 4 / 1 2 5 6 4 4}$

doi: $10.1067 / \mathrm{mtc} .2002 .125644$
Right and left heart catheterization confirmed the echocardiographic findings. There was no gradient over the aortic valve itself, and the coronary arteries were normal. Operative myectomy was proposed to the patient.

We elected to approach the subaortic muscular stenosis with the endocardiopulmonary bypass system (Johnson \& Johnson Corp, New Brunswick, NJ). Our technique for mitral valve exposure has been described elsewhere ${ }^{4}$ but is briefly summarized here.

A working port of $4 \mathrm{~cm}$ was made in the midportion of the fourth right intercostal space. A camera port was also made in the fourth intercostal space but at the level of the anterior axillary line. A venting port was made in the seventh intercostal space at the level of the anterior axillary line (this port also served for carbon dioxide insufflation). Cardiopulmonary bypass was instituted through the right groin vessels. An endoaortic balloon clamp was positioned under transesophageal echocardiographic guidance in the ascending aorta. The endoaortic balloon was progressively inflated, and cold crystalloid antegrade cardioplegia was administered. The left atrium was opened, and the mitral valve was exposed. We now detached the anterior mitral valve leaflet from its anulus and exposed the subaortic stenosis (Figure 1 ). The $30^{\circ}$ camera was turned upward to locate the right coronary cusp. This manoeuver identified very precisely the safety margins for resection. The septal hypertrophy was resected without any technical difficulty with a surgical knife (Figure 2).

A bovine pericardial patch (Biovascular Inc, St Paul, Minn) was used to reattach the anterior mitral leaflet to the anulus, and the repair was reinforced with a size 28 Carpentier-Edwards Physio ring (Edwards Lifesciences, Irvine, Calif). An immediate postoperative transesophageal echocardiogram showed the absence of mitral valve regurgitation and a residual left ventricular outflow tract gradient of $13 \mathrm{~mm} \mathrm{Hg}$.

The postoperative course was complicated by atrial fibrillation, which was converted to normal sinus rhythm with sotalol. The patient is now 5 months postoperatively in sinus rhythm and New York Heart Association functional class I. A transesophageal echocardiogram revealed a resting left ventricular outflow tract gradient of $12 \mathrm{~mm} \mathrm{Hg}$, which remains unchanged during Valsalva maneuvers (Figure 3). There is a residual trace mitral regurgitation. 


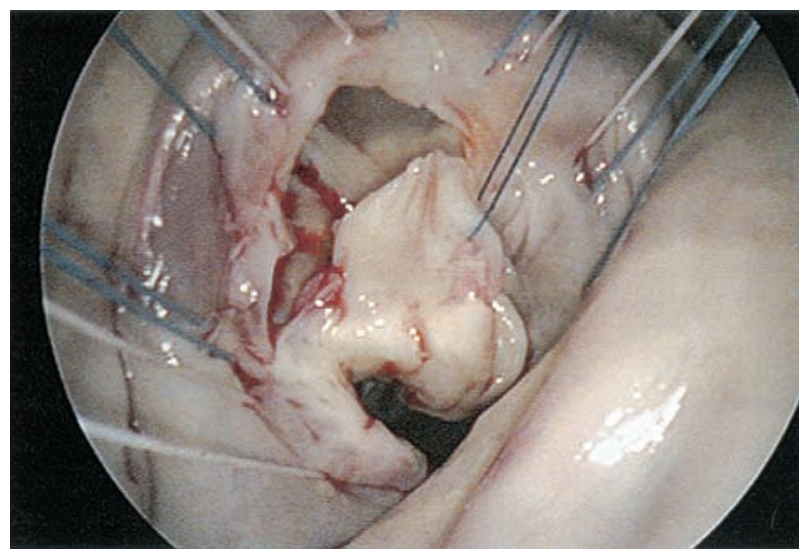

Figure 1. Exposure of the hypertrophic septum after detachment of the anterior mitral leaflet from its anulus.

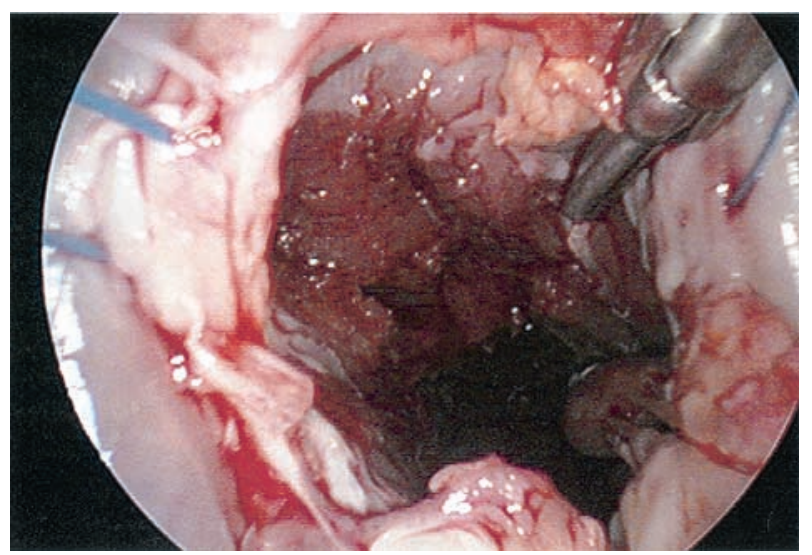

Figure 2. The septal myectomy is now completed. Note the tunnellike left ventricular outflow tract.

\section{Discussion}

Excellent results have been described for surgical relief of IHSS. ${ }^{1}$ This procedure is usually performed with a classical sternotomy. Thus far, this approach has provided the least cumbersome exposure. Indeed, aiming to reduce the invasiveness, we have tried to perform a septal myectomy through a $\mathrm{J}$ sternotomy but were disappointed with the limited exposure. In contrast, the current operative technique provides excellent exposure with complete and perfect visibility of the entire septum. Consequently, a com-

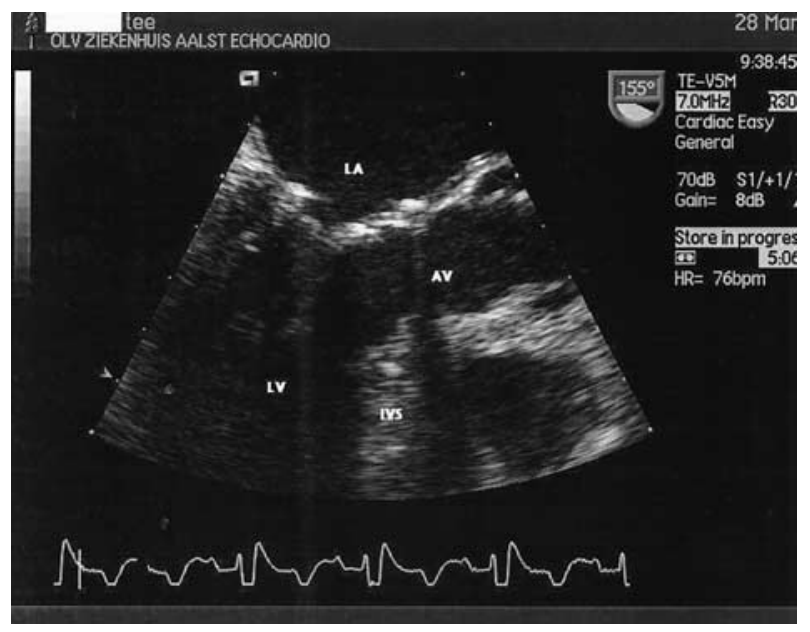

Figure 3. Long-axis equivalent image of the left ventricular outflow tract on a transesophageal echocardiogram, showing the myectomy result. $L A$, Left atrium; $L V$, left ventricle; IVS, interventricular septum; $A V$, aortic valve.

plete septal myectomy is fairly straightforward. In addition to the perfect visibility, this approach is the least invasive of all surgical techniques described.

One of the technical pitfalls of septal myectomy is the avoidance of the conduction tissue. This is obtained by starting the myectomy beneath the nadir of the right coronary cusp. To correctly locate this point with the current technique, we turned the $30^{\circ}$ camera upward to precisely identify the right coronary cusp.

In conclusion, we demonstrated that endoscopic surgical relief of IHSS with an excellent result is technically feasible and has the potential to replace the current surgical septal myectomy approach.

\section{References}

1. ten Berg JM, Suttorp MJ, Knaepen PJ, Ernst SM, Vermeulen FEE, Jaarsma W. Hypertrophic obstructive cardiomyopathy. Initial results and long-term follow-up after Morrow septal myectomy. Circulation. 1994;90:1781-5.

2. Jeanrenaud X, Goy JJ, Kappenberger L. Effects of dual-chamber pacing in hypertrophic obstructive cardiomyopathy. Lancet. 1992;339: 1318-38.

3. Maron BJ. Role of alcohol septal ablation in treatment of obstructive hypertrophic cardiomyopathy. Lancet. 2000;355:425-6.

4. Schroeyers P, Wellens F, De Geest R, Degrieck I, Van Praet F, Vermeulen $Y$, et al. Minimally invasive video-assisted mitral valve surgery: Our lessons after a 4-year experience. Ann Thorac Surg. 2001;72:S1050-4. 